\title{
Identification and Characterization of MicroRNAs in Snakehead Fish Cell Line upon Snakehead Fish Vesiculovirus Infection
}

\author{
Xiaodan Liu 1,2, ${ }^{\dagger}$, Jiagang Tu ${ }^{1,2, *, \dagger}$, Junfa Yuan ${ }^{1,2}$, Xueqin Liu ${ }^{1,2}$, Lijuan Zhao ${ }^{1,2}$, \\ Farman Ullah Dawar 1,3, Muhammad Nasir Khan Khattak ${ }^{3}$, Abeer M. Hegazy 1,4, \\ Nan Chen ${ }^{1,2}$, Vikram N. Vakharia ${ }^{5}$ and Li Lin ${ }^{1,2, *}$ \\ 1 Department of Aquatic Animal Medicine, College of Fisheries, Huazhong Agricultural University, \\ Wuhan 430070, China; 1910110526@126.com (X.L.); jfyuan@mail.hzau.edu.cn (J.Y.); \\ xueqinliu@mail.hzau.edu.cn (X.L.); zhaolijuan4234@163.com (L.Z.); farmandawar2012@yahoo.com (F.U.D.); \\ abeer@nwrc-egypt.org (A.M.H.); chennan@mail.hzau.edu.cn (N.C.) \\ 2 Freshwater Aquaculture Collaborative Innovation Center of Hubei Province, Wuhan 430070, China \\ 3 Department of Zoology, Hazara University, Mansehra, Khyber Pakhtoonkhwa 21300, Pakistan; \\ mnasir43663@googlemail.com \\ 4 Central Laboratory for Environmental Quality Monitoring (CLEQM), National Water Research Center (NWRC), \\ Cairo 13621, Egypt \\ 5 Institute of Marine and Environmental Technology, University of Maryland, Baltimore, MD 21202, USA; \\ vakharia@umbc.edu \\ * Correspondence: tujiagang@mail.hzau.edu.cn (J.T.); linli@mail.hzau.edu.cn (L.L.); \\ Tel.: +86-27-8728-4177 (J.T.); +86-27-8728-2113 (L.L.); Fax: +86-27-8728-2114 (J.T. \& L.L.) \\ + These authors contributed equally to the work.
}

Academic Editor: Jun Li

Received: 5 January 2016; Accepted: 21 January 2016; Published: 26 January 2016

\begin{abstract}
MicroRNAs (miRNAs) play important roles in mediating multiple biological processes in eukaryotes and are being increasingly studied to evaluate their roles associated with cellular changes following viral infection. Snakehead fish Vesiculovirus (SHVV) has caused mass mortality in snakehead fish during the past few years. To identify specific miRNAs involved in SHVV infection, we performed microRNA deep sequencing on a snakehead fish cell line (SSN-1) with or without SHVV infection. A total of 205 known miRNAs were identified when they were aligned with the known zebrafish miRNAs, and nine novel miRNAs were identified using MiRDeep2 software. Eighteen and 143 of the 205 known miRNAs were differentially expressed at three and $24 \mathrm{~h}$ post-infection (poi), respectively. From the differentially-expressed miRNAs, five were randomly selected to validate their expression profiles using quantitative reverse transcription polymerase chain reaction (qRT-PCR), and their expression profiles were consistent with the microRNA sequencing results. In addition, the target gene prediction of the SHVV genome was performed for the differentially-expressed host miRNAs, and a total of 10 and 58 differentially-expressed miRNAs were predicted to bind to the SHVV genome at three and $24 \mathrm{~h}$ poi, respectively. The effects of three selected miRNAs (miR-130-5p, miR-214 and miR-216b) on SHVV multiplication were evaluated using their mimics and inhibitors via qRT-PCR and Western blotting. The results showed that all three miRNAs were able to inhibit the multiplication of SHVV; whereas the mechanisms underlying the SHVV multiplication inhibited by the specific miRNAs need to be further characterized in the future.
\end{abstract}

Keywords: snakehead fish Vesiculovirus; SSN-1 cell; miRNA; deep sequencing 


\section{Introduction}

miRNAs, which are extensively expressed in various organisms, comprise a class of endogenous non-coding RNAs and post-transcriptionally regulate gene expression via translational repression and/or degradation of mRNAs by binding to complementary sequences in the $3^{\prime}$ untranslated region (UTR) of mRNAs [1-6]. MiRNAs are initially transcribed as long pri-miRNAs in the nucleus and then processed by the RNase III enzyme Drosha in the nucleus and Dicer in cytoplasm to be mature $\sim 22 \mathrm{nt}$ miRNAs [7]. To date, $>10,000$ miRNAs have been annotated in 96 species [8], including $>1000$ human miRNAs [9]. It is believed that $>50 \%$ of host mRNAs are regulated by one or more miRNAs, and individual miRNAs regulate $>100$ mRNAs [5]. miRNAs are involved in almost all biological processes in eukaryotes, including cell differentiation, apoptosis and immunity [10-12]. In addition, miRNAs are also involved in the modulation of gene expression and replication of viruses and play a pivotal role in host-virus interactions $[1,13]$. Therefore, the study of miRNA-mediated host-virus interactions is important to understand the mechanisms of virus infection and host counteraction [14].

Members of the family Rhabdoviridae, such as spring viremia of carp virus, infectious hematopoietic necrosis virus, viral hemorrhagic septicemia virus and Siniperca chuatsi rhabdovirus, have caused serious diseases in a wide variety of species in aquaculture [15-17]. In 2014, a disease outbreak occurred in hybrid snakehead fish cultured at a farm in Guangdong province, China. From the diseased snakehead fishes, a virus was isolated and determined to be Vesiculovirus via genome sequencing. The genome of snakehead Vesiculovirus (SHVV) is about $11 \mathrm{~kb}$ in length and encodes five structural proteins: nucleoprotein $(\mathrm{N})$, phosphoprotein $(\mathrm{P})$, matrix protein $(\mathrm{M})$, glycoprotein $(\mathrm{G})$ and RNA-dependent RNA polymerase protein (large protein, L) [18,19]. In addition to the genome sequence, a snakehead fish cell line SSN-1, but not a zebrafish cell line (ZF4), was able to support efficient replication of SHVV $[18,20]$. However, the pathogenic mechanism of SHVV infection is still poorly understood. Therefore, we aimed to identify the miRNA expression profile of SSN-1 cells upon SHVV infection in this study. In addition, several miRNAs of interest were chosen, and their roles in SHVV infection were further investigated.

\section{Results}

\subsection{Overview of the Illumine Hiseq2500 Sequencing Data of Small RNAs}

To investigate the miRNA expression profiles of snakehead fish cell line SSN-1 with or without SHVV infection, small RNA libraries from SHVV infected or non-infected SSN-1 cells at three and $24 \mathrm{~h}$ post-infection (poi) were sequenced by illumine Hiseq2500. About 10 million clean reads, which were passed through quality filtering, adapter filtering and length filtering, were obtained from each of the four samples, including SSN-1 cells ( $3 \mathrm{~h}$ ), SSN-1 cells infected with SHVV ( 3 h), SSN-1 cells ( $24 \mathrm{~h}$ ) and SSN-1 cells infected with SHVV (24 h) (Table S1). Given that no genome of snakehead fish was available, the unique clean reads were subjected to the alignment with the genome of zebrafish. The results showed that the aligned reads, which can be mapped to the genome of zebrafish, account for only $20 \%-40 \%$ of the total unique clean reads (Table S1). The length distribution of the clean reads was analyzed, and a similar trend of the length distribution was observed in the four samples. Most of the small RNAs were 21-23 nt in length (Figure 1).

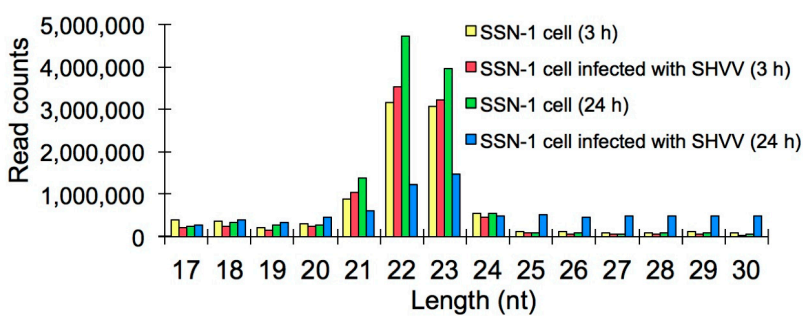

Figure 1. Length distribution of small RNAs derived from SSN-1 cells with or without snakehead fish Vesiculovirus (SHVV) infection. The small RNAs from the indicated four samples with lengths between 17 and $30 \mathrm{nt}$ are analyzed. 


\subsection{Identification of Conserved miRNAs in SSN-1 Cells}

To identify conserved miRNAs in SSN-1 cells, the data from the four samples were aligned with the known zebrafish miRNAs in miRBase 20.0. A total of 205 miRNAs belonging to 102 families were identified (Excel S1). There were 182 miRNAs from sample SSN-1 cells ( $3 \mathrm{~h}$ ), 180 miRNAs from sample SSN-1 cells infected with SHVV (3 h), 180 miRNAs from sample SSN-1 cells ( $24 \mathrm{~h}$ ) and 152 miRNAs from sample SSN-1 cells infected with SHVV (24 h) (Figure 2). Among the 205 conserved miRNAs, 143 miRNAs were present in all four samples (Figure 2). miRNAs let-7a, miR-100-5p, miR-10b-5p, miR-125b-5p, miR-146a, miR-181a-5p, miR-21, miR-27c-3p and miR-92a-3p were the most abundant miRNAs (>100,000 reads) in the four samples (Excel S1). However, the expression levels of miR-124-3p, miR-124-5p, miR-124-6-5p, miR-133a-3p, miR-133b-3p, miR-135b-3p, miR-135b-5p, miR-137-3p and some other miRNAs were rather low (Excel S1). These results indicated that the miRNAs exhibited a wide range of expression levels.

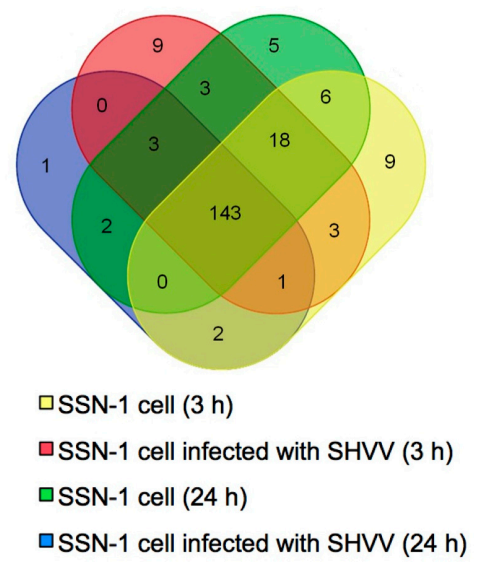

Figure 2. Identification of miRNAs compared to zebrafish miRNAs. miRNAs from the four samples were compared to the known zebrafish miRNAs in miRBase 20.0. A total of 205 known miRNAs were clustered including 182 miRNAs from sample SSN-1 cells ( $3 \mathrm{~h}$ ), 180 miRNAs from sample SSN-1 cells infected with SHVV ( $3 \mathrm{~h}$ ), 180 miRNAs from sample SSN-1 cells (24 h) and 152 miRNAs from sample SSN-1 cells infected with SHVV ( $24 \mathrm{~h}$ ). The Venn diagram shows the distribution of miRNAs of the four samples. The overlapping section represents the number of co-expressed miRNAs.

\subsection{Prediction and Validation of Novel miRNAs}

After eliminating the known miRNAs, tRNA, snRNA, rRNA, cRNA, the non-annotated small RNAs that could be mapped to the genome of zebrafish were subjected to novel miRNA prediction using MiRDeep2 software. Nine novel miRNAs were identified (Table 1). In order to validate the existence of the nine novel miRNAs, RT-PCR was used, and the size of RT-PCR products was around $100 \mathrm{bp}$ (Figure 3), indicating the existence of these novel miRNAs in SSN-1 cells.

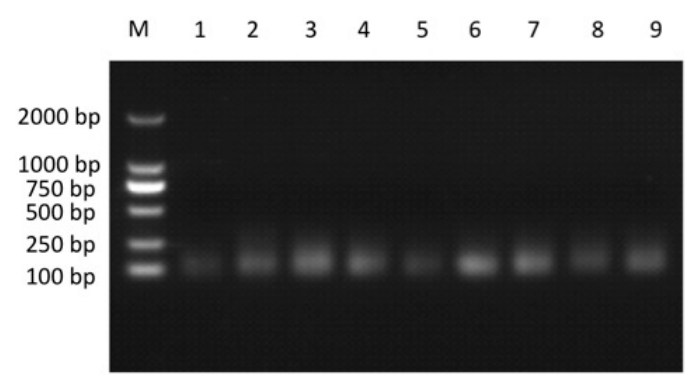

Figure 3. Validation of nine novel miRNAs by RT-PCR. M: marker; Lanes 1-9: the RT-PCR products of the nine novel miRNAs. 
Table 1. Summary of the predicted novel miRNAs.

\begin{tabular}{lcccc}
\hline & Sequence $\left(\mathbf{5}^{\prime} \rightarrow \mathbf{3}^{\prime}\right)$ & Mature Reads & Fold Change $\left(\mathbf{L o g}_{\mathbf{2}} \mathbf{I 2 4 / C 2 4}^{*}{ }^{*}\right.$ & $p$-Value \\
\hline 1 & UCCAUCAGUCACGUGACCUAC & 26 & -2.15182 & $2.03 \times 10^{-16}$ \\
2 & UCGGGUCGCUAAUGACGUCACC & 30 & -3.57979 & $4.64 \times 10^{-21}$ \\
3 & ACCAGGUGCUGUAAGCUU & 67 & $<1$ & - \\
4 & CUUUUAAUCUGAGGGUCCA & 12 & $<1$ & - \\
5 & AUGACUCGAACCCGAGGACUCG & 13 & 1.57979 & 0.019847 \\
6 & AUCCGGCUCGAAGGACCAA & 157 & -4.36217 & 0 \\
7 & AAACACUGCCAGCUGCCACA & 5 & -3.67933 & 0.00165 \\
8 & GGGGCCUGAGUCCUUCUG & 17 & 13.75742 & 0 \\
9 & ACCCCACUCCUGGUACCA & 51 & -4.59089 & $8.16 \times 10^{-197}$ \\
\hline
\end{tabular}

* I24: SSN-1 cell infected with SHVV (24 h); C24: SSN-1 cells (24 h).

\subsection{Differentially-Expressed miRNAs and Validation of the miRNAs by qRT-PCR}

The differentially-expressed miRNAs, including known and novel miRNAs between SHVV infected and non-infected SSN-1 cells, were analyzed. At three hours poi, 18 known miRNAs were differentially expressed, including 15 upregulated and three downregulated miRNAs (Table S2). No novel miRNA was differentially expressed at three hours poi. At $24 \mathrm{~h}$ poi, $150 \mathrm{miRNAs}$, including seven novel and 143 known miRNAs, were differentially expressed (Table 1 and Table S3). Of the seven novel differentially-expressed miRNAs, five were downregulated, and two were upregulated; whereas all of the 143 known differentially-expressed miRNAs were downregulated (Table S3). In order to validate the results of deep sequencing, five miRNAs, which were differentially expressed both at three and $24 \mathrm{~h}$ poi, were selected to quantify their expression via qRT-PCR. The results showed that the expression profiles of these five miRNAs were consistent with those obtained by deep sequencing (Figure 4).

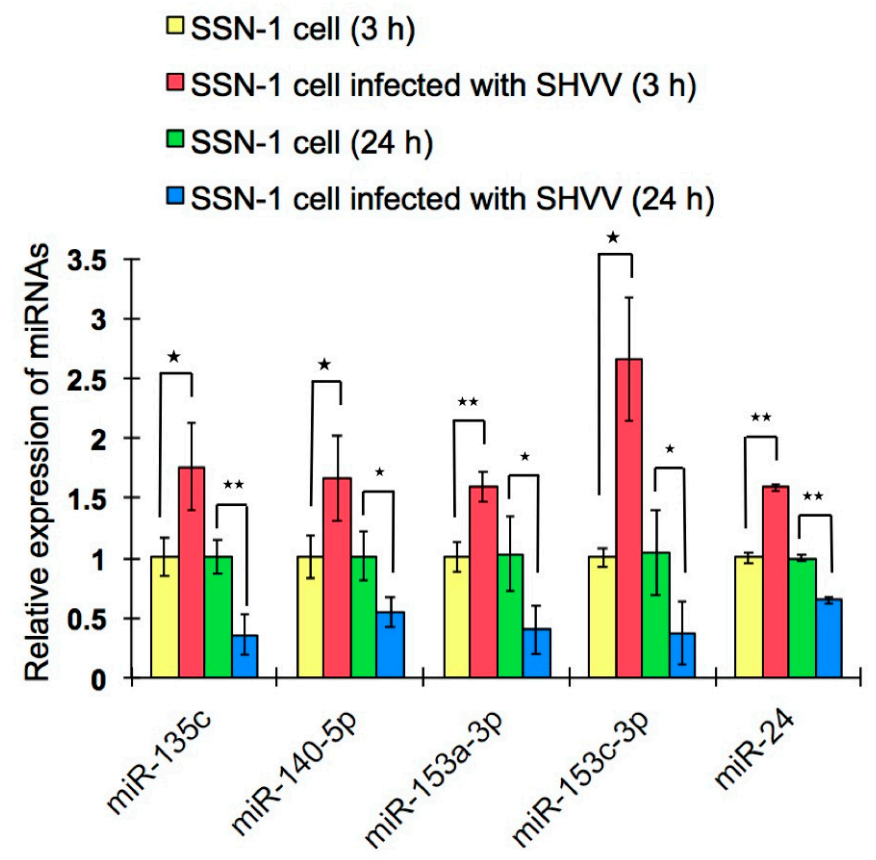

Figure 4. Expression analysis of five selected miRNAs by qRT-PCR. Five differentially-expressed miRNAs were randomly selected to quantify their expression profiles using qRT-PCR. Non-infected SSN-1 cells were used as the control. * and ${ }^{* *}$ respectively indicate statistically-significant differences between infected and non-infected samples $\left({ }^{*} p<0.05 ;{ }^{* *} p<0.01\right)$. 


\section{5. miRNA Targets Prediction}

To better understand the functions of miRNAs of snakehead fish (Channa striatus), especially their roles in SHVV multiplication, the targets of miRNA on the SHVV genome were predicted using Miranda software. At three hours poi, 10 of the 18 differentially-expressed miRNAs were predicted to bind to the SHVV genome. Most of them bind to one viral gene, except for miR-199-5p and miR-153a-3p, which were predicted to bind to two viral genes (Table S4). For the 143 differentially-expressed miRNAs at $24 \mathrm{~h}$ poi, 58 miRNAs were predicted to bind to viral genes. Twelve of them were predicted to bind to at least two genes of SHVV (Table 2). These data provided valuable information for further study on whether and how these miRNAs affect SHVV multiplication.

Table 2. Summary of targeted virus gene prediction of the differentially-expressed miRNAs when the sample SSN-1 cells infected with SHVV ( $24 \mathrm{~h}$ ) were compared to SSN-1 cells ( $24 \mathrm{~h})$.

\begin{tabular}{|c|c|c|c|}
\hline Name & Sequence $\left(5^{\prime} \rightarrow 3^{\prime}\right)$ & Target & Fold Change $\left(\log _{2}{ }^{I 24 / C 24}\right) *$ \\
\hline $\operatorname{miR}-23 a-3-5 p$ & GGAUUCCUGGCAGAGUGAUUU & $\mathrm{N}, \mathrm{L}$ & -7.92953 \\
\hline $\operatorname{miR}-199-5 p$ & CCCAGUGUUCAGACUACCUGUUC & $\mathrm{N}, \mathrm{L}$ & -3.96545 \\
\hline $\operatorname{miR}-338$ & UCCAGCAUCAGUGAUUUUGUUG & $\mathrm{N}, \mathrm{L}$ & -4.16476 \\
\hline miR-145-3p & GGAUUCCUGGAAAUACUGUUCU & $\mathrm{N}, \mathrm{L}$ & -6.05784 \\
\hline $\operatorname{miR}-100-3 p$ & CAAGCUUGUAUCUAUAGGUAUC & $\mathrm{N}, \mathrm{G}$ & -3.61793 \\
\hline miR-216b & UAAUCUCUGCAGGCAACUGUGA & $\mathrm{N}, \mathrm{G}, \mathrm{L}$ & -6.73689 \\
\hline $\operatorname{miR}-130 c-5 p$ & GCCCUUUUUCUGUUGUACUACU & $\mathrm{N}, \mathrm{G}, \mathrm{L}$ & -4.79246 \\
\hline $\operatorname{miR}-214$ & ACAGCAGGCACAGACAGGCAG & $\mathrm{N}, \mathrm{P}$ & -4.27387 \\
\hline miR-731 & AAUGACACGUUUUCUCCCGGAUCG & $\mathrm{N}$ & -3.18425 \\
\hline $\operatorname{miR}-29 b$ & UAGCACCAUUUGAAAUCAGUGU & $\mathrm{P}$ & -3.20471 \\
\hline miR-29a & UAGCACCAUUUGAAAUCGGUUA & $\mathrm{P}$ & -3.25812 \\
\hline $\operatorname{miR}-135 c$ & UAUGGCUUUCUAUUCCUAUGUG & M & -1.6469 \\
\hline $\operatorname{miR}-145-5 p$ & GUCCAGUUUUCCCAGGAAUCCC & G & -7.017 \\
\hline $\operatorname{miR}-92 b-3 p$ & UAUUGCACUCGUCCCGGCCUCC & G & -4.75081 \\
\hline $\operatorname{miR}-153 b-3 p$ & UUGCAUAGUCACAAAAAUGAGC & G, L & -2.41897 \\
\hline miR-7147 & UGUACCAUGCUGGUAGCCAGU & G & -4.7948 \\
\hline $\operatorname{miR}-92 a-3 p$ & UAUUGCACUUGUCCCGGCCUGU & G & -3.97976 \\
\hline miR-184 & UGGACGGAGAACUGAUAAGGGC & G & -2.16476 \\
\hline $\operatorname{miR}-301 c-3 p$ & CAGUGCAAUAGUAUUGUCAUAG & G & -2.45693 \\
\hline $\operatorname{miR}-363-3 p$ & AAUUGCACGGUAUCCAUCUGUA & G & -3.26429 \\
\hline $\operatorname{miR}-454 b$ & UAGUGCAAUAUUGCUUAUAGGG & G & -2.98676 \\
\hline miR-301a & CAGUGCAAUAGUAUUGUCAAAG & G & -2.1425 \\
\hline miR-130a & CAGUGCAAUGUUAAAAGGGCAU & G & -3.11229 \\
\hline $\operatorname{miR}-23 a-5 p$ & GAAUUCCUGGCAGAGUGAUUU & G, L & -6.09946 \\
\hline miR-153a-3p & UUGCAUAGUCACAAAAGUGAUC & G, L & -2.95278 \\
\hline miR-25-3p & CAUUGCACUUGUCUCGGUCUGA & G & -2.31239 \\
\hline $\operatorname{miR}-730$ & UCCUCAUUGUGCAUGCUGUGUGU & G & -4.60532 \\
\hline miR-204-5p & UUCCCUUUGUCAUCCUAUGCCU & $\mathrm{G}, \mathrm{L}$ & -3.14817 \\
\hline $\operatorname{miR}-301 b-3 p$ & CAGUGCAAUAGUAUUGUCAUUG & G & -4.92954 \\
\hline miR-724 & UUAAAGGGAAUUUGCGACUGUU & $\mathrm{L}$ & -2.63081 \\
\hline miR-181c-5p & CACAUUCAUUGCUGUCGGUGGG & $\mathrm{L}$ & -1.84696 \\
\hline $\operatorname{miR}-125 a$ & UCCCUGAGACCCUUAACCUGUG & $\mathrm{L}$ & -3.16476 \\
\hline $\operatorname{miR}-183-5 p$ & UAUGGCACUGGUAGAAUUCACUG & $\mathrm{L}$ & -1.57979 \\
\hline miR-199-3p & UACAGUAGUCUGCACAUUGGUU & $\mathrm{L}$ & -2.97786 \\
\hline $\operatorname{miR}-26 a-2-3 p$ & CCUAUUCAUGAUUACUUGCACU & $\mathrm{L}$ & -3.8599 \\
\hline $\operatorname{miR}-140-3 p$ & UACCACAGGGUAGAACCACGGAC & $\mathrm{L}$ & -3.03951 \\
\hline miR-146a & UGAGAACUGAAUUCCAUAGAUGG & $\mathrm{L}$ & -1.98658 \\
\hline miR-150 & UCUCCCAAUCCUUGUACCAGUG & $\mathrm{L}$ & -2.63751 \\
\hline $\operatorname{miR}-221-3 p$ & AGCUACAUUGUCUGCUGGGUUUC & $\mathrm{L}$ & -2.48955 \\
\hline $\operatorname{miR}-34 a^{1}$ & UGGCAGUGUCUUAGCUGGUUGU & $\mathrm{L}$ & -2.5756 \\
\hline $\operatorname{miR}-101 b$ & UACAGUACUAUGAUAACUGAAG & $\mathrm{L}$ & -2.73747 \\
\hline miR-9-5p & UCUUUGGUUAUCUAGCUGUAUGA & $\mathrm{L}$ & -1.54182 \\
\hline
\end{tabular}


Table 2. Cont.

\begin{tabular}{|c|c|c|c|}
\hline Name & Sequence $\left(5^{\prime} \rightarrow 3^{\prime}\right)$ & Target & Fold Change $\left(\log _{2}{ }^{I 24 / C 24}\right) *$ \\
\hline miR-181b-5p & AACAUUCAUUGCUGUCGGUGGG & $\mathrm{L}$ & -1.75554 \\
\hline miR-107a-3p & AGCAGCAUUGUACAGGGCUAUCA & $\mathrm{L}$ & -2.81985 \\
\hline miR-101a & UACAGUACUGUGAUAACUGAAG & $\mathrm{L}$ & -3.05599 \\
\hline $\operatorname{miR}-181 c-3 p$ & CUCGCCGGACAAUGAAUGAGAA & $\mathrm{L}$ & -5.01275 \\
\hline miR-103 & AGCAGCAUUGUACAGGGCUAUGA & $\mathrm{L}$ & -2.61915 \\
\hline miR-146b & UGAGAACUGAAUUCCAAGGGUG & $\mathrm{L}$ & -3.91539 \\
\hline $\operatorname{miR}-138-5 p$ & AGCUGGUGUUGUGAAUCAGGCC & $\mathrm{L}$ & -4.94236 \\
\hline $\operatorname{miR}-429 a$ & UAAUACUGUCUGGUAAUGCCGU & $\mathrm{L}$ & -2.44487 \\
\hline miR-153b-5p & GUCAUUUUUGUGGUUUGCAGCU & $\mathrm{L}$ & -3.67933 \\
\hline $\operatorname{miR}-125 c-5 p$ & UCCCUGAGACCCUAACUCGUGA & $\mathrm{L}$ & -5.07926 \\
\hline $\operatorname{miR}-181 a-5 p$ & AACAUUCAACGCUGUCGGUGAGU & $\mathrm{L}$ & -1.97076 \\
\hline miR-199-3-3p & ACAGUAGUCCGCACAUUGGUU & $\mathrm{L}$ & -3.81683 \\
\hline miR-125b-5p & UCCCUGAGACCCUAACUUGUGA & $\mathrm{L}$ & -3.43276 \\
\hline $\operatorname{miR}-26 a-5 p$ & UUCAAGUAAUCCAGGAUAGGCU & $\mathrm{L}$ & -3.35436 \\
\hline miR-722 & UUUUUUGCAGAAACGUUUCAGAUU & $\mathrm{L}$ & -6.25146 \\
\hline $\operatorname{miR}-222 a-3 p$ & AGCUACAUCUGGCUACUGGGUCUC & $\mathrm{L}$ & -3.55456 \\
\hline
\end{tabular}

* I24: SSN-1 cells infected with SHVV (24 h); C24: SSN-1 cells (24 h); N: nucleoprotein; P: phosphoprotein; M: matrix protein; G: glycoprotein; L: RNA-dependent RNA polymerase protein (large protein).

\subsection{Effects of Three Selected miRNAs on SHVV Multiplication}

Three differentially-expressed miRNAs, including miR-130-5p, miR-214 and miR-216b, were chosen to evaluate their effects on SHVV multiplication. miR-130-5p and miR-216b were predicted to bind to N, G and L genes, while miR-214 was predicted to bind to N and P genes (Table 2). The mimics and inhibitors of the three miRNAs were used to treat SSN-1 cells followed by SHVV infection. The results of qRT-PCR showed that all three miRNAs exhibited significant inhibitory effects on mRNA expression of the $\mathrm{N}$ gene, while for the $\mathrm{P}$ gene, only miR-130c-5p and miR-214 exhibited inhibitory effects (Figure 5A). Among the three miRNAs, miR-214 exhibited the most significant inhibitory effect (Figure 5A). Western blotting was also performed to evaluate the effects of these three miRNAs on protein expression of $\mathrm{N}$ and P genes. Similar to the effects on mRNA expression of SHVV, miR-130c-5p and miR-214 also exhibited a significant inhibitory effect on protein expression of SHVV. Together, these data demonstrated the three miRNAs, at least miR-130c-5p and miR-214, could efficiently repress SHVV multiplication.

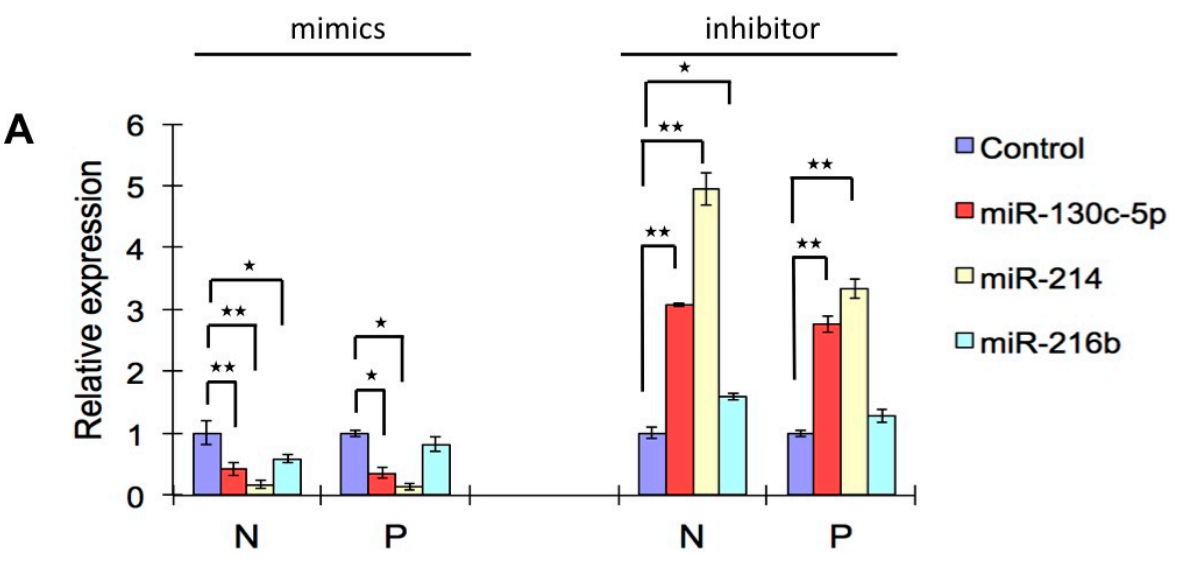

Figure 5. Cont. 


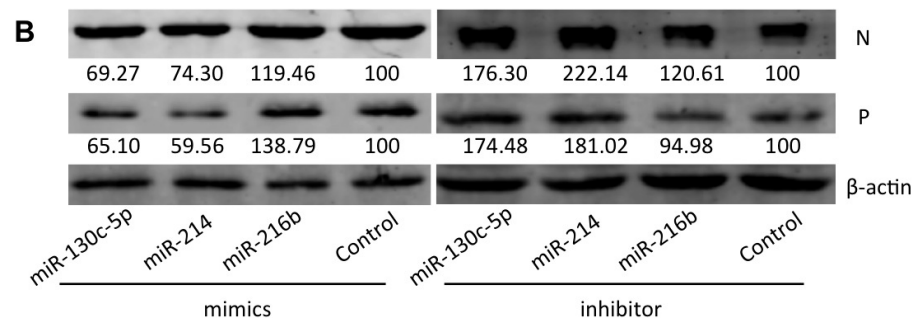

Figure 5. Effects of three differentially-expressed miRNAs on SHVV multiplication. (A) Quantification of mRNA level of $\mathrm{N}$ and $\mathrm{P}$ genes of SHVV via qRT-PCR. The mimics or inhibitors of three selected miRNAs, as well as the mimic control or the inhibitor control were transfected into SSN-1 cells followed by SHVV infection. * and ${ }^{* *}$ respectively indicate statistically-significant differences between infected and non-infected samples ( $p<0.05$; ${ }^{* *} p<0.01$ ); (B) Detection of protein level of $\mathrm{N}$ and $\mathrm{P}$ genes of SHVV via Western blotting. $\beta$-actin was used as the internal control protein. The integrated optical densities of the protein bands were measured using Image-Pro Plus 6.0. The value of the $\mathrm{N}$ and $\mathrm{P}$ protein bands are normalized to $\beta$-actin. The value of the $\mathrm{N}$ and $\mathrm{P}$ protein bands of the control were set as 100 , while the values of the $\mathrm{N}$ and $\mathrm{P}$ protein bands of the three miRNAs were compared to that of the control.

\section{Discussion}

Although miRNAs are widely expressed in a variety of organisms, their expression profiles vary greatly among tissues [21]. For example, miR-122 is highly expressed in hepatocytes, but is absent in almost all other cells [22]. Therefore, different miRNA expression profiles might be acquired when we use different tissues from the same organism. The miRNA expression profile of several teleost fishes has recently been identified in different tissues, including bighead carp and silver carp [23], common carp [24], blunt snout bream [25] and epithelial cells of carp [14]. Since SHVV could infect and replicate in several tissues of snakehead fish [18], we choose SNN-1 cells, which are derived from a whole snakehead fry fish [26], to study the differential miRNA expression profile of snakehead fish upon SHVV infection.

Upon infection, viruses encounter a large number of miRNAs expressed in host cells. Differentially-expressed miRNAs pre- and post-virus infection may be associated with viral infection [27]. In this study, we identified 143 known and seven novel differentially-expressed miRNAs in SSN-1 cells upon SHVV infection at $24 \mathrm{~h}$ poi. Interestingly, all of the 143 known differentially-expressed miRNAs were downregulated (Table S3). However, two of the seven novel miRNAs were upregulated and five were downregulated (Table 1), and the reasons are not known. Functional confirmation of the 150 differentially-expressed miRNAs in SSN-1 cells to facilitate or repress virus multiplication is needed.

Multiple reports have revealed that miRNAs regulate virus replication by targeting key elements of innate immunity. miR-136 regulates host antiviral innate immunity by acting as an immune agonist of retinoic acid-inducible gene 1 (RIG-1) [28]. miR-146 was identified as a regulator of enterovirus replication by targeting key elements of the MyD88 signal pathway [29]. In addition, miRNAs also mediate antiviral defense by targeting viral transcripts. miR-122 stimulates translation of hepatitis $\mathrm{C}$ virus RNA through interaction with the $3^{\prime}$ UTRs of viral genome [30]. miR-181 can directly impair porcine reproductive and respiratory syndrome virus replication via specifically binding to a conserved region in the downstream of open reading frame 4 of the viral genomic RNA [31]. miR-let-7c inhibits H1N1 influenza virus replication by targeting the $3^{\prime}$ UTR of the M1 genome and represses M1 protein expression [32]. In this study, three downregulated miRNAs that were predicted to target two or three genes of SHVV were selected to determine their effects on virus multiplication. All three miRNAs exhibited significant antiviral properties. In addition to binding to the SHVV genome, these three miRNAs were predicted to target tens of host genes (data not shown). Some of the predicted host 
genes are involved in antiviral signal pathways. Therefore, it is possible that these miRNAs utilize both direct and indirect ways to suppress SHVV multiplication. Further studies are needed to understand the exact mechanisms of the inhibition.

The miRNA was not exclusively host miRNA, many viruses can encode viral miRNAs, which not only facilitate viral replication, but also help the virus to counteract host immune response. Based on the ability of viral miRNA production, viruses can be divided into three categories: the herpesviruses, which encode multiple viral miRNAs; the nuclear DNA viruses, which may encode one or two miRNAs; the RNA viruses and cytoplasmic DNA viruses, which appear to lack any miRNAs [7]. In this study, no miRNA encoded by SHVV was identified. The probable reason behind this seems to be that SHVV is an RNA virus.

\section{Experimental Section}

\subsection{Virus, Cells and RNA Preparation}

SHVV was isolated from diseased hybrid snakehead fish and stored at $-80{ }^{\circ} \mathrm{C}$. SSN-1 cells, kindly provided by Hong Liu from Shenzhen Animal \& Plant Inspection and Quarantine Technology Center, were cultured in minimum essential medium (HyClone, Logan, UT, USA) supplemented with $10 \%$ fetal bovine serum (Gibco, Auckland, New Zealand) and penicillin (100 $\mu \mathrm{g} / \mathrm{mL})$, streptomycin $(100 \mu \mathrm{g} / \mathrm{mL})$ at $25^{\circ} \mathrm{C}$. To prepare RNA sample, SSN-1 cells were grown on four 6-well plastic dishes (Costar, Corning, NY, USA). Two 6-well plastic dishes was infected with 0.1 multiplicity of infection (MOI) of SHVV; the other two were used as uninfected controls with an equal volume of PBS. At 3 and $24 \mathrm{~h}$ poi, SHVV infected and non-infected SSN-1 cells were collected in TRIzol reagent (Invitrogen, Carlsbad, CA, USA) for the total RNA extraction according to the manufacturer's instructions.

\subsection{Small RNA Library Construction}

The RNA samples were subjected to $15 \%$ polyacrylamide gel electrophoresis (PAGE) for the enrichment of molecules with a length of 17-30 nt [14]. After $5^{\prime}$ and $3^{\prime}$ adaptors were added, RT-PCR with adaptor-specific primers was used to generate a small RNA library from SHVV-infected and non-infected SSN-1 cells at 3 and $24 \mathrm{~h}$ poi. The small RNA library was then sequenced by illumine Hiseq2500.

\subsection{Sequencing Data Analysis}

The raw reads were counted and the clean reads of four samples, including SSN-1 cells ( $3 \mathrm{~h}$ ), SSN-1 cells infected with SHVV ( 3 h), SSN-1 cells ( $24 \mathrm{~h}$ ) and SSN-1 cells infected with SHVV ( $24 \mathrm{~h}$ ), were acquired by excluding low-quality reads, $3^{\prime}$ adapter reads, $5^{\prime}$ adapter reads and poly(A) sequences. The length distribution of the clean reads was calculated, and the clean reads were aligned with the genome of zebra fish. Conserved miRNAs were identified by aligning the small RNAs of the four samples to the Zebrafish miRNAs data in miRBase Version 20.0 [33].

\subsection{Identification of Novel miRNAs}

MiRDeep2 software was used to identify potential novel miRNAs from the four samples. Overlapping sequences were used to form longer sequences according to their alignments to known precursor sequences in the miRBase. The differentially-expressed novel miRNAs were summarized between SHVV-infected and non-infected SSN-1 cells.

\subsection{Analysis of Differentially-Expressed miRNAs}

The identified miRNAs in the four samples were analyzed to identify differentially-expressed miRNAs between SHVV-infected and non-infected SSN-1 cells. The fold change higher than 2 and a $p$-value $<0.05$ were the criteria to select differentially-expressed miRNAs. 


\subsection{Prediction of miRNA Targets on the SHVV Genome}

The miRNA targets on the SHVV genome were predicted using Miranda software [34].

\subsection{RT-PCR and qRT-PCR Analysis of miRNAs}

The predicted novel miRNAs were validated by RT-PCR as described previously [14]. Five randomly-selected miRNAs were detected by qRT-PCR using the same RNA samples used for the construction of the miRNA library. Five forward primers were designed based on mature miRNA sequences (Table S5). A 20-bp segment at the $3^{\prime}$ end of the 5S rRNA gene was amplified as an endogenous control to normalize template amounts. Quantitative PCR reactions were conducted in $20-\mu \mathrm{L}$ volumes containing $1 \mu \mathrm{L}$ diluted cDNA, $300 \mathrm{nM}$ of each primer and $10 \mu \mathrm{L}$ of the SYBR Master Mix with the following cycling conditions: $95^{\circ} \mathrm{C}$ for $5 \mathrm{~min}, 45$ cycles at $95^{\circ} \mathrm{C}$ for $10 \mathrm{~s}, 58^{\circ} \mathrm{C}$ for $10 \mathrm{~s}$ and $72{ }^{\circ} \mathrm{C}$ for $15 \mathrm{~s}$, and ended with a $95^{\circ} \mathrm{C}$ at $5{ }^{\circ} \mathrm{C} / \mathrm{s}$ calefactive velocity to make the melt curve. All expression levels were normalized to the arithmetic mean of the selected $5 \mathrm{~S}$ ribosomal RNA gene. Amplification results were analyzed using a comparative $C_{\mathrm{t}}$ method, which uses a formula $2^{-\Delta \Delta C t}$ to achieve results for relative quantification. $C_{t}$ represents the threshold cycle.

\subsection{Effects of Three Randomly-Selected Differentially-Expressed miRNAs on Virus Multiplication}

SSN-1 cells in 12-well plates were transfected with $100 \mathrm{nM}$ mimics or $50 \mathrm{nM}$ inhibitors of miR-130c-5p, miR-214, miR-216b, as well as mimic control or inhibitor control using Lipofectamine 2000 (Invitrogen, USA). The inhibitor is the single-strand RNA that is completely paired to miRNAs. At $24 \mathrm{~h}$ post-transfection, the cells were infected with $0.1 \mathrm{MOI}$ of SHVV for $24 \mathrm{~h}$. The cells were harvested to determine the effects of three miRNA mimics or inhibitors on virus mRNA expression by qRT-PCR and protein expression by Western blotting.

Supplementary Materials: Supplementary materials can be found at http:/ /www.mdpi.com/1422-0067/17/ 2/154/s1.

Acknowledgments: This work was jointly supported by Natural Science Foundation of China (31572657, 31372563), the Huazhong Agricultural University Scientific \& Technological Self-innovation Foundation (52204-12020), the Fundamental Research Funds for the Central Universities (2013PY069, 2014PY035) and the Special funds for science and technology from Hubei Province (2015BBA228).

Author Contributions: Li Lin and Jiagang Tu designed the research. Li Lin, Jiagang Tu, Junfa Yuan, Xueqin Liu, Muhammad Nasir Khan Khattak and Vikram N. Vakhara finalized the paper writing. Xiaodan Liu, Lijuan Zhao, Farman Ullah Dawar, Abeer M. Hegaz and Nan Chen performed the experiments and contributed to the data collection, as well as the statistical analysis.

Conflicts of Interest: The authors declare no conflict of interest.

\section{References}

1. Fan, H.X.; Tang, H. Complex interactions between microRNAs and hepatitis B/C viruses. World J. Gastroenterol. 2014, 20, 13477-13492. [CrossRef] [PubMed]

2. Wang, X.G.; Yu, J.F.; Zhang, Y.; Gong, D.Q.; Gu, Z.L. Identification and characterization of microRNA from chicken adipose tissue and skeletal muscle. Poult. Sci. 2012, 91, 139-149. [CrossRef] [PubMed]

3. Djuranovic, S.; Nahvi, A.; Green, R. miRNA-mediated gene silencing by translational repression followed by mRNA deadenylation and decay. Science 2012, 336, 237-240. [CrossRef] [PubMed]

4. Trakooljul, N.; Hicks, J.A.; Liu, H.C. Identification of target genes and pathways associated with chicken microRNA miR-143. Anim. Genet. 2010, 41, 357-364. [PubMed]

5. Bartel, D.P. MicroRNAs, target recognition and regulatory functions. Cell 2009, 136, 215-233. [CrossRef] [PubMed]

6. Doench, J.G.; Sharp, P.A. Specificity of microRNA target selection in translational repression. Genes Dev. 2004, 18, 504-511. [CrossRef] [PubMed]

7. Cullen, B.R. Five questions about viruses and microRNAs. PLoS Pathog. 2010, 6, e1000787. [CrossRef] [PubMed] 
8. Skalsky, R.L.; Cullen, B.R. Viruses, microRNAs, and host interactions. Annu. Rev. Microbiol. 2010, 64, $123-141$. [CrossRef] [PubMed]

9. Cullen, B.R. Viruses and microRNAs, RISCy interactions with serious consequences. Genes Dev. 2011, 25, 1881-1894. [CrossRef] [PubMed]

10. Xiao, C.; Calado, D.P.; Galler, G.; Thai, T.H.; Patterson, H.C.; Wang, J.; Rajewsky, N.; Bender, T.P.; Rajewsky, K. MiR-150 controls B cell differentiation by targeting the transcription factor c-Myb. Cell 2007, 131, 146-159. [CrossRef] [PubMed]

11. Xu, P.; Vernooy, S.Y.; Guo, M.; Hay, B.A. The Drosophila microRNA Mir-14 suppresses cell death and is required for normal fat metabolism. Curr. Biol. 2003, 13, 790-795. [CrossRef]

12. Ou, J.; Meng, Q.; Li, Y.; Xiu, Y.; Du, J.; Gu, W.; Wu, T.; Li, W.; Ding, Z.; Wang, W. Identification and comparative analysis of the Eriocheir sinensis microRNA transcriptome response to Spiroplasma eriocheiris infection using a deep sequencing approach. Fish Shellfish Immunol. 2012, 32, 345-352. [CrossRef] [PubMed]

13. Trobaugh, D.W.; Gardner, C.L.; Sun, C.; Haddow, A.D.; Wang, E.; Chapnik, E.; Mildner, A.; Weaver, S.C.; Ryman, K.D.; Klimstra, W.B. RNA viruses can hijack vertebrate microRNAs to suppress innate immunity. Nature 2014, 506, 245-248. [CrossRef] [PubMed]

14. Wu, S.; Liu, L.; Zohaib, A.; Lin, L.; Yuan, J.; Wang, M.; Liu, X. MicroRNA profile analysis of Epithelioma papulosum cyprini cell line before and after SVCV infection. Dev. Comp. Immunol. 2015, 48, 124-128. [CrossRef] [PubMed]

15. Betts, A.M.; Stone, D.M.; Way, K.; Torhy, C.; Chilmonczyk, S.; Benmansour, A.; de Kinkelin, P. Emerging vesiculo-type virus infections of freshwater fishes in Europe. Dis. Aquat. Organ. 2003, 57, 201-212. [CrossRef] [PubMed]

16. Crane, M.; Hyatt, A. Viruses of fish, an overview of significant pathogens. Viruses 2011, 3, $2025-2046$. [CrossRef] [PubMed]

17. McFee, R.B. Global infections-Avian influenza and other significant emerging pathogens: An overview. Dis. Mon. 2007, 53, 343-347. [CrossRef] [PubMed]

18. Liu, X.; Wen, Y.; Hu, X.; Wang, W.; Liang, X.; Li, J.; Vakharia, V.; Lin, L. Breaking the host range: Mandarin fish is susceptible to a vesiculovirus derived from snakehead fish. J. Gen. Virol. 2015, 96, 775-781. [CrossRef] [PubMed]

19. Zeng, W.; Wang, Q.; Wang, Y.; Liu, C.; Liang, H.; Fang, X.; Wu, S. Genomic characterization and taxonomic position of a rhabdovirus from a hybrid snakehead. Arch. Virol. 2014, 159, 2469-2473. [CrossRef] [PubMed]

20. Wang, W.; Asim, M.; Yi, L.; Hegazy, A.M.; Hu, X.; Zhou, Y.; Ai, T.; Lin, L. Abortive infection of snakehead fish vesiculovirus in ZF4 cells was associated with the RLRs pathway activation by viral replicative intermediates. Int. J. Mol. Sci. 2015, 16, 6235-6250. [CrossRef] [PubMed]

21. Landgraf, P.; Rusu, M.; Sheridan, R.; Sewer, A.; Iovino, N.; Aravin, A.; Pfeffer, S.; Rice, A.; Kamphorst, A.O.; Landthaler, M.; et al. A mammalian microRNA expression atlas based on small RNA library sequencing. Cell 2007, 129, 1401-1414. [CrossRef] [PubMed]

22. Cullen, B.R. How do viruses avoid inhibition by endogenous cellular microRNAs? PLoS Pathog. 2013, 9, e1003694. [CrossRef] [PubMed]

23. Chi, W.; Tong, C.; Gan, X.; He, S. Characterization and comparative profiling of MiRNA transcriptomes in bighead carp and silver carp. PLoS ONE 2011, 6, e23549. [CrossRef] [PubMed]

24. Yan, X.; Ding, L.; Li, Y.; Zhang, X.; Liang, Y.; Sun, X.; Teng, C.B. Identification and profiling of microRNAs from skeletal muscle of the common carp. PLOS ONE 2012, 7, e30925. [CrossRef] [PubMed]

25. Yi, S.; Gao, Z.X.; Zhao, H.; Zeng, C.; Luo, W.; Chen, B.; Wang, W.M. Identification and characterization of microRNAs involved in growth of blunt snout bream (Megalobrama amblycephala) by Solexa sequencing. BMC Genom. 2013, 14, 754. [CrossRef] [PubMed]

26. Frerichs, G.N.; Morgan, D.; Hart, D.; Skerrow, C.; Roberts, R.J.; Onions, D.E. Spontaneously productive C-type retrovirus infection of fish cell lines. J. Gen. Virol. 1991, 72, 2537-2539. [CrossRef] [PubMed]

27. Li, Z.J.; Zhang, Y.P.; Li, Y.; Zheng, H.W.; Zheng, Y.S.; Liu, C.J. Distinct expression pattern of miRNAs in Marek's disease virus infected-chicken splenic tumors and non-tumorous spleen tissues. Res. Vet. Sci. 2014, 97, 156-161. [CrossRef] [PubMed]

28. Zhao, L.; Zhu, J.; Zhou, H.; Zhao, Z.; Zou, Z.; Liu, X.; Lin, X.; Zhang, X.; Deng, X.; Wang, R.; et al. Identification of cellular microRNA-136 as a dual regulator of RIG-I-mediated innate immunity that antagonizes H5N1 IAV replication in A549 cells. Sci. Rep. 2015, 5, 14991. [CrossRef] [PubMed] 
29. Taganov, K.D.; Boldin, M.P.; Chang, K.J.; Baltimore, D. NF-kB-dependent induction of microRNA miR-146, an inhibitor targeted to signaling proteins of innate immune responses. Proc. Natl. Acad. Sci. USA 2006, 103, 12481-12486. [CrossRef] [PubMed]

30. Henke, J.I.; Goergen, D.; Zheng, J.; Song, Y.; Schuttler, C.G.; Fehr, C.; Junemann, C.; Niepmann, M. microRNA-122 stimulates translation of hepatitis C virus RNA. EMBO J. 2008, 27, 3300-3310. [CrossRef] [PubMed]

31. Guo, X.K.; Zhang, Q.; Gao, L.; Li, N.; Chen, X.X.; Feng, W.H. Increasing expression of microRNA 181 inhibits porcine reproductive and respiratory syndrome virus replication and has implications for controlling virus infection. J. Virol. 2013, 87, 1159-1171. [CrossRef] [PubMed]

32. Ma, Y.J.; Yang, J.; Fan, X.L.; Zhao, H.B.; Hu, W.; Li, Z.P.; Yu, G.C.; Ding, X.R.; Wang, J.Z.; Bo, X.C.; et al. Cellular microRNA let-7c inhibits M1 protein expression of the H1N1 influenza A virus in infected human lung epithelial cells. J. Cell. Mol. Med. 2012, 16, 2539-2546. [CrossRef] [PubMed]

33. miRBase. Available online: http://www.mirbase.org (accessed on 1 January 2016).

34. Miranda. Available online: http://www.microrna.org/microrna/home.do (accessed on 1 January 2016).

(C) 2016 by the authors; licensee MDPI, Basel, Switzerland. This article is an open access article distributed under the terms and conditions of the Creative Commons by Attribution (CC-BY) license (http://creativecommons.org/licenses/by/4.0/). 